\title{
The effect of ground limestone on the properties of composite gypsum binder using thermally activated clay as a pozzolanic component
}

\author{
Marat Khaliullin ${ }^{10000-0003-0038-0077]}$, and Alsu Gilmanshina*1[0000-0001-6473-1812] \\ ${ }^{1}$ Kazan State University of Architecture and Engineering, 420043 Kazan, Russia
}

\begin{abstract}
The purpose of this research is to study the effect of methods of preliminary preparation of thermally activated clay, which is a pozzolanic component in water-resistant composite gypsum binders, as well as the effect of mechanochemical activation in the joint grinding of thermally activated clay with the addition of a plasticizer on the pozzolanic activity and the change in the required number of pozzolanic component in the composition of composite gypsum binders. It was found that the required amount of thermally activated clay as pozzolanic component in the gypsum-cement-pozzolan composition when ground to specific surfaces of $200-500 \mathrm{~m}^{2} / \mathrm{kg}$ together with the addition of Melflux $2651 \mathrm{~F}$ plasticizer, based on the exclusion of conditions for the formation of an unacceptable amount of ettringite, decreases by $20-25 \%$ compared with the use of thermally activated clay ground without the introduction of a plasticizer. The optimal amount of Melflux $2651 \mathrm{~F}$ plasticizer introduced by grinding with thermally activated clay has been determined. The significance of the results for the construction industry lies in the fact that the use of the technology of obtaining composite gypsum binders of grinding thermally activated clay to a certain dispersion with the introduction of a plasticizer additive due to the effect of mechanochemical activation makes it possible to reduce the consumption of the pozzolanic component in the binder composition or energy consumption for grinding.
\end{abstract}

Keywords. Plasticizer, composite gypsum binder, gypsum-cementpozzolanic composition, thermally activated clay.

\section{Introduction}

Gypsum building materials and products are characterized by low energy consumption and cost effectiveness in production, sustainability, and a wide range of raw materials. The disadvantage of traditional gypsum building materials is low water resistance and strength, which limits the range and scope of their application.

In the last decade, research on studying the effect of plasticizer additives on the properties of gypsum compositions gained traction: based on lignosulfonates and their modified varieties, sulfonated naphthalene- and melamine-formaldehyde compounds and complexes based on them, superplasticizer C-3 based on polycondensation products of naphthalenosulfonic acid and formaldehyde, based on polycarboxylates [1-5]. The

*Corresponding author: a.dimieva@bk.ru 
introduction of plasticizing additives makes it possible to increase the density, strength and water resistance of hardened compositions based on gypsum binders. Water-resistant composite gypsum binders of high strength were developed on the basis of the earlier studies in the development of the principles previously proposed by A.V. Volzhensky, A.V. Ferronskaya and other scientists. Composite gypsum binders are obtained by mixing gypsum binder with a complex of modifying components. Portland cement or lime, pozzolanically active finely dispersed silica-containing materials (for example, microsilica, zeolitecontaining rocks, slags, ash, quartz sand, cullet, brick or ceramic powder, expanded clay dust, etc.), plasticizers, and mineral fillers and other functional additives can also be added to composite gypsum binders composition in a certain ratio [6-11].

Efficient and affordable pozzolanic additives for the production of composite gypsum binders are ground thermally activated clays (TAC), including large-tonnage waste from the construction industry which is expanded clay dust [12-14]. At the same time, the technological process for obtaining composite gypsum binders using TAC as a pozzolanic component can provide for the following methods (Fig. 1):

- mixing with other dosed components of composite gypsum binders, including the addition of a plasticizer in a powdered aggregate state, TAC, previously separately ground to the required degree of dispersion;

- mixing with other components of composite gypsum binders of TAC, pre-ground to the required degree of dispersion together with a dosed addition of a plasticizer in a powdered aggregate state in the amount accepted for obtaining a binder.

$1^{\text {st }}$ METHOD OF OBTAINING

COMPOSITE GYPSUM BINDER

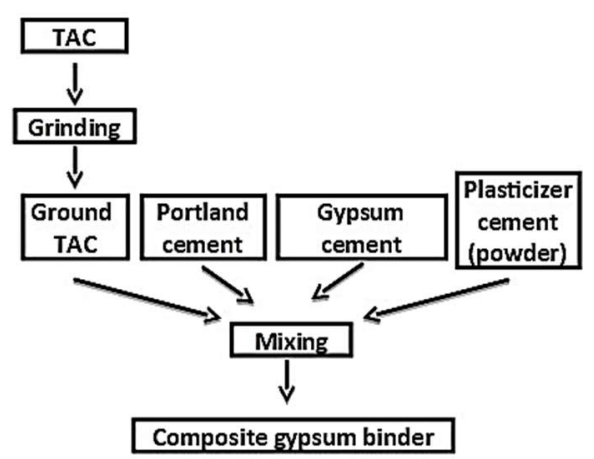

$2^{\text {nd }}$ METHOD OF OBTAINING

COMPOSITE GYPSUM BINDER

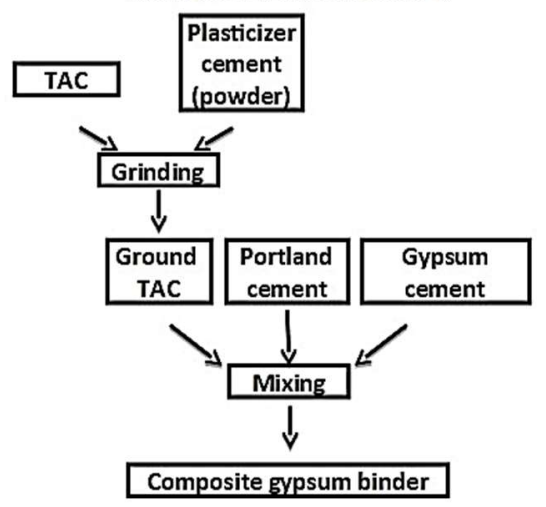

Fig. 1. Types of methods for organizing the technological process of obtaining composite gypsum binders (illustration by the authors).

The purpose of this paper is to assess the effect of the methods of preliminary preparation of TAC for obtaining composite gypsum binders with grinding to achieve a certain dispersion without the introduction and with the introduction of a plasticizer during grinding, as well as the effect of mechanochemical activation, realized during joint grinding with the addition of a plasticizer, on pozzolanic activity and, accordingly, the change in the required amount of the pozzolanic component in composite gypsum binders composition.

\section{Materials and methods}

TAC of the Saray-Chekurchinsky deposit calcinated at $400{ }^{\circ} \mathrm{C}$ during 4 hours was used as a pozzolanic component in the gypsum cement pozzolanic composition in the composite gypsum binder. 
The quantitative chemical composition of the initial clay was determined using an ARL OPTYMX spectrometer.

The chemical composition of clay includes: $\mathrm{SiO}_{2}-68,52 ; \mathrm{Al}_{2} \mathrm{O}_{3}-13,42 ; \mathrm{Fe}_{2} \mathrm{O}_{3}-6,18$; $\mathrm{TiO}_{2}-0,86 ; \mathrm{MnO}-0,10 ; \mathrm{CaO}-1,33 ; \mathrm{MgO}-1,66 ; \mathrm{Na}_{2} \mathrm{O}-1,20 ; \mathrm{K}_{2} \mathrm{O}-1,82 ; \mathrm{P}_{2} \mathrm{O}_{5}-0,99$; $\mathrm{SO}_{3} / \mathrm{S}<0,05$; ignition loss $-4,62 ; \mathrm{H}_{2} \mathrm{O}-3,41$ (in $\%$ by weight).

To determine the mineral composition of the initial clay, X-ray phase analysis was carried out using a D8 Advance diffractometer (Bruker).

The mineral composition of the clay includes: quartz -28 , mica -10 , orthoclase -7 , plagioclase -8 , mixed-layered clay mineral, chloride -1 (all in $\%$ by weight). Mixed-layered mineral contains up to $40 \%$ non-swelling layers.

The granulometric composition includes: clay particles -49.5 ; dusty particles -37.1 ; sand particles - 13.4 (content of fractions in \% by weight).

The TAC was ground in a laboratory planetary mill to achieve specific surfaces of 200 , 350 , and $500 \mathrm{~m}^{2} / \mathrm{kg}$.

To obtain the gypsum cement pozzolanic composition together with TAC, we used G5BII building gypsum according to State Standards (GOST) 125 produced by the Volgograd gypsum plant of the Volma Corporation, and Portland cement manufactured by Mordovcement JSC 500-D0-N according to GOST 10178.

To carry out the research, we used a plasticizing additive Melflux $2651 \mathrm{~F}$ on a polycarboxylate basis in a powdered state (manufactured by BASF Construction Polymers).

Determination of the required amount of TAC in the gypsum cement pozzolanic composition was carried out based on the method proposed in Moscow Engineering and Construction Institute named after V.V. Kuibyshev and based on the ability of pozzolanic additives to absorb calcium hydroxide from its saturated solution in the study of special preparations, which are aqueous suspensions of semi-aqueous gypsum, Portland cement and pozzolanic additives.

Composite gypsum binder tests were carried out in accordance with GOST 23789. After manufacturing, artificial stone samples were stored for 28 days in a normal hardening chamber and were dried at $55{ }^{\circ} \mathrm{C}$ to constant weight before testing. The softening coefficient was determined according to TU 21-0284757.

\section{Results and discussions}

The first stage of the study included research of the effect of the amount of Melflux $2651 \mathrm{~F}$ plasticizer additive introduced to the gypsum cement pozzolanic composition on the change in the indicators of the main physical and mechanical properties of the obtained composite gypsum binder and artificial stone based on it (Table 1).

Table 1. Effect of the amount of the Melflux $2651 \mathrm{~F}$ plasticizer additive on the basic physical and mechanical properties of composite gypsum binder.

\begin{tabular}{|c|c|c|c|c|c|c|}
\hline $\begin{array}{c}\text { № } \\
\text { composition }\end{array}$ & $\begin{array}{c}\text { Amount of } \\
\text { additive, \% }\end{array}$ & $\begin{array}{c}\text { Normal } \\
\text { consistency, \% }\end{array}$ & $\begin{array}{c}\text { Average } \\
\text { density, } \\
\mathrm{kg} / \mathrm{m}^{3}\end{array}$ & $\begin{array}{c}\text { Compressive } \\
\text { strength, MPa }\end{array}$ & $\begin{array}{c}\text { Water } \\
\text { absorption, \% }\end{array}$ & $\begin{array}{c}\text { Softening } \\
\text { coefficient }\end{array}$ \\
\hline 1 & 0 & 51 & 1380 & 19.2 & 24.5 & 0.72 \\
\hline 2 & 0.25 & 36 & 1572 & 32.9 & 15.0 & 0.81 \\
\hline 3 & 0.5 & 27 & 1858 & 41.0 & 9.9 & 0.86 \\
\hline 4 & 0.75 & 26 & 1995 & 47.2 & 8.9 & 0.91 \\
\hline 5 & 1 & 25 & 2016 & 47.5 & 8.4 & 0.92 \\
\hline
\end{tabular}

According to the research results presented in Table 1, the optimal amount of the Melflux $2651 \mathrm{~F}$ plasticizer introduced to the gypsum cement pozzolanic composition is $0.5-0.75 \%$ by weight. The introduction of the optimal amount of plasticizer additive in comparison with the control composition without plasticizer introduction makes it possible to reduce the 
normal consistence of the gypsum cement pozzolanic composition by $24-25 \%$, providing during the hardening the formation of artificial stone with a denser structure, characterized by an increase in the average density by $35-45 \%$ and a decrease in water absorption by $14.6-$ $15.6 \%$, an increase in compressive strength 2.1-2.5 times, a softening coefficient from 0.72 (gypsum binders with increased water resistance) to 0.86-0.91 (water resistant gypsum binders). With an increase in the content of the plasticizer additive in the gypsum cement pozzolanic composition from 0.75 to $1 \%$, there is a further slight increase in the indicators of the main physical and mechanical properties of composite gypsum binder.

The second stage of the study included research of the effects of the methods of preliminary preparation of TAC for obtaining composite gypsum binder, which consisted in grinding TAC to achieve a certain dispersion, without the introduction and with the introduction of Melflux $2651 \mathrm{~F}$ plasticizer during the grinding process, on the change in the required amount of pozzolanic additive in the gypsum cement pozzolanic composition (Fig. 2-4).

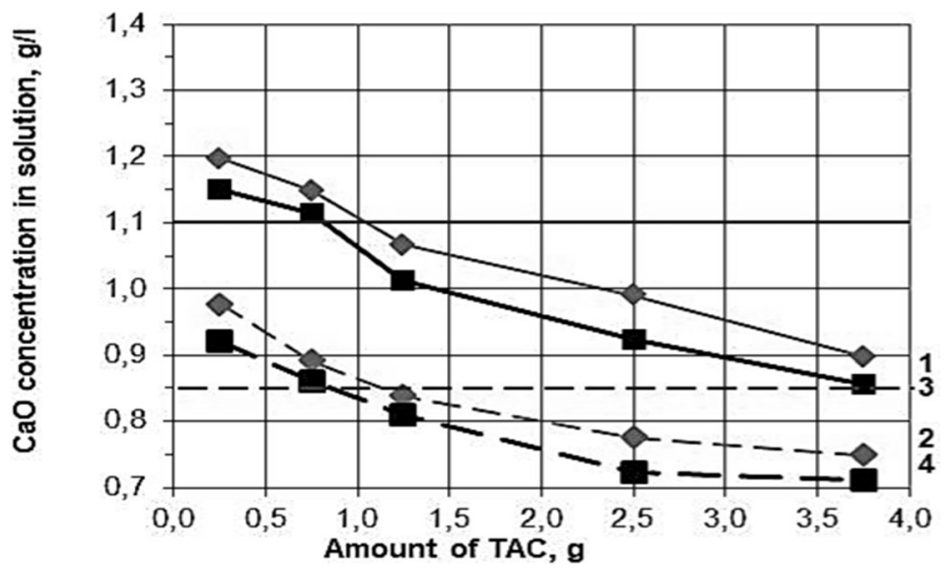

Fig. 2. Kinetics of $\mathrm{CaO}$ absorption by adding $\mathrm{TAC}$ at a specific surface area of $150 \mathrm{~m}^{2} / \mathrm{kg}$. Concentration of $\mathrm{CaO}$ in solution for samples: $1,3-5$ days old; $2,4-7$ days old. Method of preliminary preparation of TAC: 1,2 - with grinding without plasticizer introduction; 2, 3-with grinding with plasticizer introduction (authors illustration).

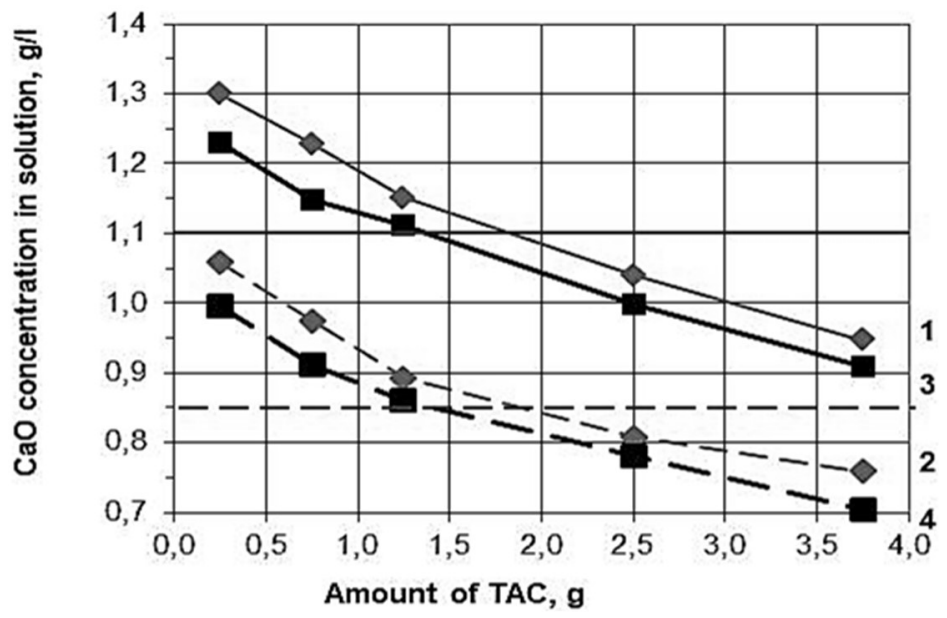

Fig. 3. Kinetics of $\mathrm{CaO}$ absorption by adding TAC at a specific surface area of $300 \mathrm{~m}^{2} / \mathrm{kg}$. Concentration of $\mathrm{CaO}$ in solution for samples: $1,3-5$ days old; $2,4-7$ days old. Method of preliminary preparation of TAC: 1,2 - with grinding without plasticizer introduction; 2, 3- with grinding with plasticizer introduction (authors illustration). 


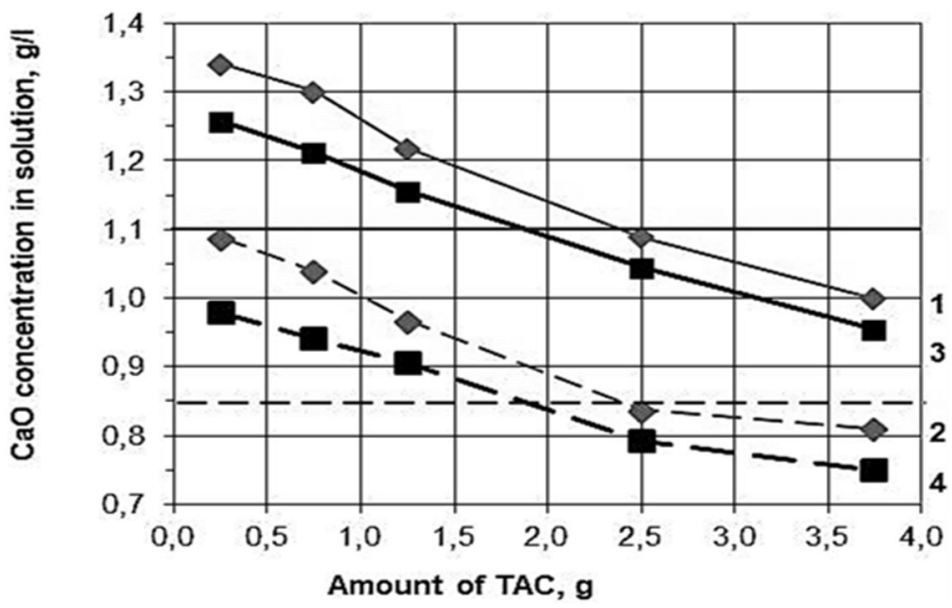

Fig. 4. Kinetics of $\mathrm{CaO}$ absorption by adding $\mathrm{TAC}$ at a specific surface area of $500 \mathrm{~m}^{2} / \mathrm{kg}$. Concentration of $\mathrm{CaO}$ in solution for samples: $1,3-5$ days old; $2,4-7$ days old. Method of preliminary preparation of TAC: 1,2 - with grinding without plasticizer introduction; 2, 3- with grinding with plasticizer introduction (authors illustration).

During individual grinding of TAC, plasticizer additive Melflux $2651 \mathrm{~F}$ was introduced into the studied gypsum cement pozzolanic composition by mixing the components. For both options, based on the results of the above studies, the optimal amount of plasticizer additive was introduced, which was $0.75 \%$ of the weight of the gypsum cement pozzolanic composition.

As a result of the studies, the results of which are shown in Fig. 2-4, the required amounts of $\mathrm{TAC}$ in the gypsum cement pozzolanic composition were determined depending on the method of preliminary preparation of TAC for obtaining composite gypsum binder and the specific surface area of the pozzolanic component achieved during the grinding process (Table 2).

Table 2. Effect of the method of preliminary preparation of TAC for obtaining composite gypsum binder on the change in the required amount of pozzolanic additive in the gypsum cement pozzolanic composition.

\begin{tabular}{|c|c|c|}
\hline \multirow{2}{*}{$\begin{array}{c}\text { Specifix surface of TAC, } \\
\mathrm{m}^{2} / \mathrm{kg}\end{array}$} & $\begin{array}{c}\text { The required amount of TAC, \% of the mass of Portland cement, } \\
\text { depending on the method of preliminary preparation of TAC to } \\
\text { obtain composite gypsum binder }\end{array}$ \\
\cline { 2 - 3 } & $\begin{array}{c}\text { without the plasticizer } \\
\text { introduction in grinding }\end{array}$ & $\begin{array}{c}\text { with the plasticizer } \\
\text { introduction in grinding }\end{array}$ \\
\hline 200 & 100 & 80 \\
\hline 350 & 80 & 60 \\
\hline 500 & 50 & 40 \\
\hline 800 & 30 & - \\
\hline
\end{tabular}

According to the research results presented in Table 2, the required amount of TAC in the gypsum cement pozzolanic composition when ground to specific surfaces of $200-500 \mathrm{~m}^{2} / \mathrm{kg}$ together with the introduction of a plasticizer is reduced by $20-25 \%$ compared to the use of ground TAC without the introduction of a plasticizer. This allows us to reduce the consumption of the pozzolanic component in the composite gypsum binder composition or the energy consumption for grinding.

An increase in the pozzolanic activity of TAC during grinding together with the addition of a plasticizer, by analogy with the processes occurring when obtaining binders of low water demand, is probably due to the effect of mechanochemical activation $[15,16]$, the ability of the plasticizer encapsulated on the surface of the particles of the ground pozzolanic 
component to prevent their aggregation and increase uniformity of their distribution in the dough when mixing composite gypsum binder with water $[17,18]$.

The developed composite gypsum binder with the use of thermally activated clay can be used in the development of raw mix compositions adapted for construction 3D printing [19, 20].

\section{Conclusion}

1. When obtaining composite gypsum binder based on gypsum cement pozzolanic composition with TAC as a pozzolanic component, it is more effective to introduce TAC into composite gypsum binder ground together with a plasticizing additive to the required specific surface area in comparison with mixing the preliminary prepared composite gypsum binder components.

2. The required amount of TAC as a pozzolanic component in the gypsum cement pozzolanic composition when grinding TAC to specific surfaces of 200-500 $\mathrm{m}^{2} / \mathrm{kg}$ together with the addition of Melflux $2651 \mathrm{~F}$ plasticizer is reduced by $20-25 \%$ compared to the use of ground TAC without adding a plasticizer. This makes it possible to reduce the consumption of the pozzolanic component in composite gypsum binder composition or the energy consumption for grinding.

3. An increase in the pozzolanic activity of TAC during grinding together with the addition of a plasticizer can be due to the effect of mechanochemical activation, as well as the ability of the addition of a plasticizer encapsulated on the surface of the particles of the ground pozzolanic component, to prevent their aggregation and to increase the uniformity of their distribution in the binder dough.

4. The optimal amount of Melflux $2651 \mathrm{~F}$ plasticizer when co-ground with TAC is 0.5 $0.75 \%$ of the weight of the gypsum cement pozzolanic composition. At the same time, a plasticizing effect is achieved with a decrease in the water consumption of composite gypsum binder by $24-25 \%$, an increase in the density of the hardened artificial stone based on it by $35-45 \%$, a decrease in water absorption by 14.6-15.6\%, an increase in compressive strength by 2.1-2.5 times, a softening coefficient up to $0.86-0.91$ and corresponding to the indicators of water-resistant gypsum binders.

\section{References}

1. V.B. Petropavlovskaya, M.Yu. Zavadko, K.S. Petropavlovskii, T.B. Novichenkova, A.F. Buryanov, Stroitelnye materialy 1-2, 28 (2019).

2. R.A. Ibragimov, E.V. Korolev, T.R. Deberdeev, Vestnik MGSU 14-3, 293 (2019). DOI: 10.22227/1997-0935.2019.3.293-300.

3. N.N. Morozova, G.V. Kuznetsova, N.V. Maysuradze, R.R. Akhtariev, L.R. Abdrashitova, E. R. Nizamutdinova, Stroitelnye materialy 8, 26 (2018).

4. R.K. Mukhametrakhimov, A.R. Galautdinov, ZKG International 11, 52 (2018).

5. R.K. Mukhametrakhimov et al. Water-resistant fiber-reinforced gypsum cementpozzolanic composites, E3S Web of Conferences. DOI: 10.1051/e3sconf/201913801011.

6. Yu.M. Bazhenov, L.H. Zagorodnjuk, V.S. Lesovik, I.V. Yerofeyeva, N.V. Chernysheva, D.A. Sumskoy, International Journal of Pharmacy and Technology 8, 22649 (2016).

7. Yu.V. Tokarev, E.O. Ginchitsky, Yu.N. Ginchitskaya, A.F. Gordina, G.I. Yakovlev, Stroitelnye materialy 1-2, 84 (2016).

8. V.V. Belov, A.F. Buryanov, G.I. Yakovlev, V.B. Petropavlovskaya, H.B. Fisher, I.S. Maeva, T.B. Novichenkova Modification of the structure and properties of building composites based on calcium sulfate, (2012).

9. R.K. Mukhametrakhimov, A.R. Galautdinov, L.V. Lukmanova. Influence of active mineral additives on the basic properties of the gypsum cementpozzolan binder for the 
manufacture of building products, MATEC Web of Conferences 106, (2017). DOI: 10.1051/matecconf/201710603012.

10. R.K. Mukhametrakhimov, A.R. Galautdinov, I.R. Gilmanshin. Modified gypsum-cementpozzolanic composites reinforced with polypropylene fibers, IOP Conference Series: Materials Science and Engineering, (2019). DOI: 10.1088/1757-899X/570/1/012068.

11. R.K. Mukhametrakhimov, L.V. Lukmanova, I.R. Gilmanshin. Physical and mechanical properties of fiber reinforced gypsum-based composite, IOP Conference Series: Materials Science and Engineering, (2019). DOI: 10.1088/1757-899X/570/1/012112.

12. M.I. Khaliullin, R.Z. Rakhimov, I.I. Faizrakhmanov, ZKG International 5, 58 (2017).

13. M.I. Khaliullin, A.I. Dimieva, Composite gypsum binder under introducing thermally activated clay as a pozzolanic component and adding ground limestone. IOP Conference Series: Materials Science and Engineering DOI: 10.1088/1757-899X/890/1/012093

14. N.R. Rakhimova, R.Z. Rakhimov, A.R. Gaifullin, V.P. Morozov, L.I. Potapova, A.M. GubaidullinA, Y.N. Osin,. Journal of Non-Crystalline Solids. 492, 1 (2018). DOI: 10.1016/j.jnoncrysol.2018.04.015

15. R.K. Mukhametrakhimov, A.R. Galautdinov, Izvestiya KGASU 1 (43), 187 (2018).

16. E.A. Vdovin, V.F. Stroganov, N.V. Konovalov, Lecture Notes in Civil Engineering. 150, 335 (2021). DOI: 10.1007/978-3-030-72404-7_33.

17. V.P. Kuzmina, Mechanical chemistry in concrete (2013).

18. V.I. Kalashnikov, M.N. Moroz, O.V. Tarakanov, D.V. Kalashnikov, O.V. Suzdaltsev, Stroitelnye materialy 9, 70 (2014).

19. R.K. Mukhametrakhimov, L.V. Lukmanova Influence of the technological properties of cement-sand mortar on the quality of $3 D$ printed products, IOP Conference Series: Materials Science and Engineering, (2020). DOI: 10.1088/1757-899X/890/1/012082.

20. R.K. Mukhametrakhimov, L.V. Lukmanova, Magazine of Civil Engineering 2, 10206. 